\title{
KAJIAN KONSEP DIAMOND FRAUD THEORY DALAM MENUNJANG EFEKTIVITAS PENGADAAN BARANG/JASA \\ DI PEMERINTAH KOTA BOGOR
}

JURNAL

MANAJEMEN

Edy Purwanto ${ }^{1}$, Dr. JMV. Mulyadi, SE., MM ${ }^{2}$, Dr. Choirul Anwar, SE, MBA,MAFIS,CPA,Ak ${ }^{3}$

INDONESIA

${ }^{1}$ Universitas Pancasila, ${ }^{2}$ Universitas Pancasila, ${ }^{3}$ Universitas Negeri Jakarta edipurwanto8275@yahoo.com

Vol.17 No.3

Desember 2017

\begin{abstract}
Abstrak
Penelitian ini bertujuan untuk menganalisis seberapa besar konsep diamond fraud theory dalam menunjang efektivitas pengadaan barang/jasa di Pemerintah Kota Bogor. Sampel yang digunakan dalam penelitian ini sebanyak 130 auditor yang terdiri dari 35 orang auditor Inspektorat Kota Bogor, 45 orang auditor Inspektorat Provinsi Jawa Barat, 30 orang auditor Badan Pengawasan Keuangan dan Pembangunan Provinsi Jawa Barat, dan 20 orang auditor Badan Pemeriksa Keuangan Perwakilan Provinsi Jawa Barat yang memenuhi kriteria penelitian yaitu auditor yang pernah bertugas memeriksa di Kota Bogor, karena penelitian ini menggunakan metode purposive sampling dalam pemilihan sampel. Sedangkan metode analisis data menggunakan teknik regresi linear berganda (multiple linear regression) dengan bantuan aplikasi SPSS 22. Hasil penelitian secara uji silmultan (Uji F) diperoleh bahwa pressure, opportunity, rationalization, dan capability secara simultan berpengaruh terhadap fraud pengadaan barang/jasa di Pemerintah Kota Bogor, hasil penelitian secara parsial (uji t) diperoleh bahwa pressure berpengaruh negatif dan signifikan terhadap fraud pengadaan barang/jasa di Pemerintah Kota Bogor sedangkan opportunity, rationalization, dan capability berpengaruh positif dan signifikan terhadap fraud pengadaan barang/jasa di Pemerintah Kota Bogor dimana tingkat kesalahan yang digunakan adalah 5\% atau 0,05 pada taraf signifikan 95\%.
\end{abstract}

Kata Kunci: pressure, opportunity, rationalization, capability, dan fraud pengadaan barang jasa pemerintah.

\begin{abstract}
This study aims to analyze how big the concept of diamond fraud theory in supporting the effectiveness of procurement of goods/services in the City Government of Bogor.The sample used in this study were 130 auditors consisting of 35 auditors of Inspectorate of Bogor City, 45 auditors of West Java Provincial Inspectorate, 30 auditors from the Supervisory Board of Finance and Development of West Java Province, and 20 auditors from the Supreme Audit Agency of West Java which meets the criteria of the research that auditors have been tasked to examine in the city of Bogor, because this study uses purposive sampling method in the selection of samples. While the method of data analysis using multiple linear regression techniques (multiple linear regressions) with the help of SPSS 22 applications. The result of the research by the test of silmultan (Test F) found that the pressure, opportunity, rationalization, and capability simultaneously affect the fraud of procurement of goods/services in Bogor City Government, partial research results ( $t$ test) obtained that the pressure has a negative and significant effect on fraud procurement of goods/services in Bogor City Government while opportunity, rationalization, and capability have positive and significant impact to fraud procurement of goods/services in Bogor City Government. Where the error rate used is 5\% or 0.05 at a significant level of $95 \%$.
\end{abstract}

Keywords: pressure, opportunity, rationalization, capability, and fraud procurement of goods/services 


\section{Pendahuluan}

Pengadaan barang jasa pemerintah sering diidentikan dengan berbagai jenis kecurangan (fraud), baik dalam proses perencanaan, proses pelaksanaan hingga penyelesaian akhir pengadaan. Kejaksaan Negeri (Kejari) Bogor kembali menahan pejabat Pemerintah Bogor yang terlibat kasus dugaan mark up (penggelembungan) dana pengadaan lahan Pasar Jambu Dua yang terjadi pada akhir tahun 2014. Yang saat itu melaksanakan pembebasan lahan untuk program penataan Pedagang Kaki Lima (PKL) yang nantinya akan dimasukkan ke pasar tersebut. Dan pada tahun 2017 Kejaksaan Negeri (Kejari) Bogor kembali menahan 2 (dua) direktur utama yang bergerak dibidang kontruksi dan Pejabat dilingkungan Pemerintah Kota Bogor, menurut Kepala kejaksaan Negeri Kota Bogor akibat korupsi pekerjaan pembangunan talud tersebut kerugian Negara mencapai Rp. 2,4 miliar yang disebabkan karena pekerjaan yang tidak sesuai dengan spesifikasi. Fenomena fraud pada pengadaan barang/jasa pemerintah dapat diamati melalui proses perencanaan, proses pelaksanaan hingga penyelesaian akhir pengadaan barang/jasa pemerintah daerah, dan dalam kurun waktu dari tahun 2013 sampai dengan 2017 terdapat 7 (tujuh) kasus pengadaan di pemerintah Kota Bogor. Demikian pula halnya dengan Pemerintah Kota Bogor sebagai kota yang dekat dengan ibukota tentunya Kota Bogor memiliki konsentrasi kegiatan perekonomian yang tinggi pada sektor barang dan jasa. Belum efektifnya pengadaan barang jasa pemerintah Kota Bogor sehingga pengadaan barang jasa Kota Bogor tidak terlepas dari berbagai macam permasalahan.

Cressey (1953) menyatakan bahwa ada tiga penyebab atau pemicu terjadinya fraud yaitu tekanan (pressure), kesempatan/peluang (opportunity), dan rasionalisasi (rationalization). Wolfe dan Hermanson (2004) mengatakan selain menangani pressure, opportunity, dan rationalization juga harus mempertimbangkan capability (kemampuan) yaitu sifat-sifat pribadi dan kemampuan yang memainkan peran utama dalam kecurangan yang mungkin benar-benar terjadi bahkan dengan kehadiran tiga unsur lainnya. Keempat elemen ini dikenal sebagai Fraud Diamond Theory (FDT). Berbagai bukti empiris yang telah didapatkan untuk menunjukkan faktor-faktor penyebab kecurangan pengadaan barang jasa antara lain penelitian Manossoh (2016) menunjukkan bahwa pressure, opportunity, rationalization, dan system berpengaruh negatif dan signifikan terhadap fraud pada pengadaaan barang/jasa pemerintah. Kusuma dan Suranta (2017) menyatakan bahwa capability, rationalization tidak berpengaruh negatif dan signifikan terhadap fraud, sedangkan pressure, opportunity berpengaruh negatif dan signifikan terhadap fraud. Amaliah dkk (2016), mengatakan bahwa pressure, rationalization tidak berpengaruh negatif dan signifikan terhadap fraud sedangkan opportunity dan capability berpengaruh negatif dan signifikan terhadap fraud. Gelderman et.al (2006) menunjukkan bahwa pemahaman pejabat pengadaan terhadap peraturan.

Rijckeghem dan Weder (1997) menunjukkan adanya hubungan yang negatif dan signifikan antara penghasilan aparatur pemerintah dengan tingkat korupsi. Penelitian Artantri et al. (2016) menyatakan bahwa e-procurement telah berhasil berperan dalam pencegahan fraud pada pengadaan barang/jasa. Penelitian Jatiningtyas dan Kiswara (2011) menyatakan bahwa dari sudut pandang pihak internal instansi, kualitas panitia pengadaan tidak berpengaruh signifikan terhadap fraud pengadaan barang/jasa. Mansor (2015) menyatakan bahwa fraud dipengaruhi Fraud Triangle Theory and Fraud Diamond Theory. Penelitian Rinie et al. (2015) mengatakan bahwa fraud pengadaan barang/ jasa dipengaruhi karakteristik pokja ULP/pejabat pengadaan dan sistem pengendalian intern, namun tidak dipengaruhi oleh kesesuaian kompensasi.

Berdasarkan latar belakang masalah diatas penulis tertarik untuk menganalisis kembali faktor-faktor yang mempengaruhi fraud pengadaan barang/jasa pada Pemerintah Kota Bogor. Perbedaan dari penelitian terdahulu adalah penelitian ini menggunakan variabel independen pressure, opportunity, rationalization dan capability. Berdasarkan uraian yang telah disajikan diatas maka rumusan masalah penelitian adalah "Seberapa besar pengaruh pressure, opportunity, rationalization dan capability secara simultan dan parsial terhadap fraud pengadaan barang/jasa pada Pemerintah Kota Bogor?" 


\section{Kajian Teori Dan Pengembangan Hipotesis}

\subsection{Teori Legitimasi (Legitimacy theory)}

Dowling dan Pfeffer (1975), legitimasi adalah hal yang penting bagi organisasi, batasanbatasan yang ditekankan oleh norma-norma dan nilai-nilai sosial, dan reaksi terhadap batasan tersebut mendorong pentingnya analisis perilaku organisasi dengan memperhatikan lingkungan. Deegan (2013), dalam perspektif teori legitimasi, suatu perusahaan akan secara sukarela melaporkan aktifitasnya jika manajemen menganggap bahwa hal ini adalah yang diharapkan komunitas. Ghozali dan Chariri (2007) menyatakan bahwa hal yang mendasari teori legitimasi adalah kontrak sosial antara perusahaan dengan masyarakat dimana perusahaan beroperasi dan menggunakan sumber ekonomi. Shocker dan Sethi (1973) memberikan penjelasan tentang konsep kontrak sosial, yaitu:

"sетиа institusi sosial tidak terkecuali perusahaan beroperasi di masyarakat melalui kontrak sosial, baik eksplisit maupun implisit, dimana kelangsungan hidup pertumbuhannya didasarkan pada hasil akhir yang secara sosial dapat diberikan kepada masyarakat luas dan distribusi manfaat ekonomi, sosial atau politik kepada kelompok sesuai dengan power yang dimiliki."

\subsection{Triangle Fraud Theory}

Dalam penelitian Cressey (1950) memutuskan untuk mewawancarai pelaku kecurangan yang menjadi tahanan atas tindakan kecurangan berupa penggelapan. Cressey mewawancarai 200 pelaku penggelapan yang sedang menjalani masa tahanan. Satu dari tujuan utama penelitian ini menyimpulkan bahwa setiap kecurangan yang dilakukan oleh para pelaku memenuhi tiga faktor penting sebagai faktor pemicu kecurangan, yaitu tiga elemen penting ada secara bersama - sama yakni pressure (dorongan/tekanan), opportunity (peluang), dan rationalization (rasionalisasi).

\subsection{Diamond Fraud Theory}

Fraud diamond merupakan pandangan baru tentang fraud yang dikemukakan oleh Wolfe dan Hermanson (2004), teori tersebut merupakan suatu bentuk penyempurnaan dari triangle fraud theory yang dikemukakan oleh Cressey (1950) dimana fraud diamond menambahkan satu elemen kualitatif yang diyakini memiliki pengaruh signifikan terhadap fraud yakni capability, bahwa untuk meningkatkan pencegahan dan pendeteksian kecurangan perlu mempertimbangkan elemen keempat. Selain menangani pressure, opportunity, dan rationalization juga harus mempertimbangkan indivual's capability (kemampuan individu) yaitu sifat-sifat pribadi dan kemampuan yang memainkan peran utama dalam kecurangan yang mungkin benar-benar terjadi bahkan dengan kehadiran tiga unsur lainnya.

\subsection{Pengertian Pengadaan Barang dan Jasa}

Pengadaan Barang dan Jasa adalah kegiatan untuk memperoleh Barang dan Jasa oleh Kementerian, Lembaga, Satuan Kerja Perangkat Daerah, Institusi Lainnya yang prosesnya dimulai dari perencanaan kebutuhan sampai diselesaikannya seluruh kegiatan untuk memperoleh Barang /Jasa (Peraturan Presiden Nomor 4 Tahun 2015 perubahan ke empat atas Peraturan Presiden Nomor 54 tahun 2010 tentang Pengadaan Barang/Jasa Pemerintah). 


\subsection{Kerangka Pemikiran}

Kerangka pemikiran dalam penelitian ini adalah:

\section{JURNAL}

MANAJEMEN

INDONESIA

\section{Vol.17 No.3}

Desember 2017

Gambar 1 Kerangka Pemikiran

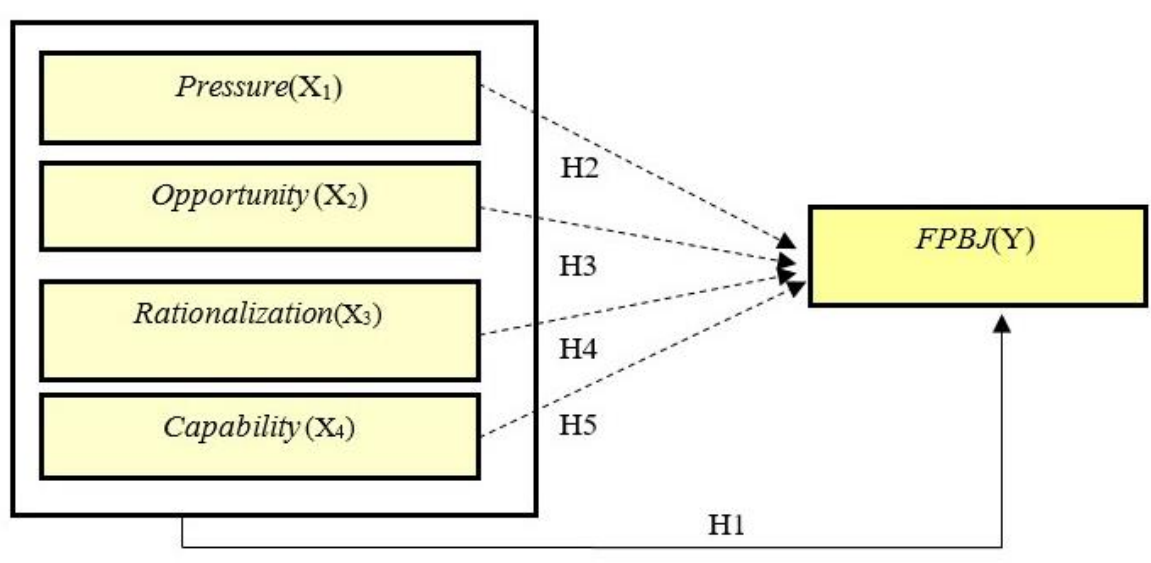

Keterangan:

1. Pressure, opportunity, rationalization dan capability berpengaruh terhadap fraud Pengadaan Barang/Jasa pada Pemerintah Kota Bogor.

2. Pressure sebagai variabel $\mathrm{X}_{1}$ berpengaruh terhadap fraud pengadaan barang/jasa pemerintah Kota Bogor.

3. Opportunity sebagai variabel $\mathrm{X}_{2}$ berpengaruh terhadap fraud pengadaan barang/jasa pemerintah Kota Bogor.

4. Rationalization sebagai variable $\mathrm{X}_{3}$ berpengaruh terhadap fraud pengadaan barang/jasa pemerintah Kota Bogor.

5. Capability sebagai variable $\mathrm{X}_{4}$ berpengaruh terhadap fraud pengadaan barang/jasa pemerintah Kota Bogor.

\section{Metode Penelitian}

Penelitian ini termasuk dalam jenis penelitian explanatory, yaitu penelitian yang dilakukan untuk menguji hubungan antar variabel yang dihipotesiskan, penelitian ini dirancang untuk mengamati dan mengetahui apakah mempunyai pengaruh variabel independen, yaitu pressure, opportunity, rationalization dan capability terhadap variabel dependent fraud pengadaan barang/jasa pemerintah. Populasi dalam penelitian ini yaitu pegawai yang bertugas di Inspektorat Kota Bogor, Inspektorat Provinsi Jawa Barat, Badan Pengawasan Keuangan dan Pembangunan Provinsi Jawa Barat dan Badan Pemeriksa Keuangan (BPK) Perwakilan Provinsi Jawa Barat, yang berjumlah 612 orang, teknik pengambilan sampel dalam penelitian ini adalah nonprobability yaitu purposive sampling yang merupakan teknik pengambilan sampel berdasarkan suatu pertimbangan/kriteria tertentu sesuai dengan yang dikehendaki peneliti (Sugiyono, 2006). Pertimbangan tertentu dalam penelitian ini adalah auditor yang pernah bertugas mengaudit proses maupun pelaksanaan pengadaan barang jasa pemerintah di Kota Bogor. Sampel dalam penelitian ini 114 responden yang terdiri dari auditor yang pernah bertugas mengaudit di Pemerintah Kota Bogor.

\subsection{Metode pengumpulan data}

Penelitian ini dilakukan melalui studi kepustakaan atau studi literatur dengan cara mempelajari, dan mengkaji literatur berupa buku-buku, peraturan perundang-undangan, artikel, dan penelitian-penelitian sebelumnya yang memiliki hubungan dengan masalah yang diteliti. Studi Lapang (Field Research) dengan kuesioner, yaitu teknik pengumpulan data dengan memberikan daftar pertanyaan kepada responden yang telah ditentukan sebagai sumber data dalam penelitian yang dilakukan, dimana kuesioner dirancang bersifat tertutup artinya setiap

Jurnal Manajemen Indonesia 
pertanyaan disediakan alternatif jawaban, sehingga responden memilih alternatif jawaban sesuai dengan yang telah disediakan.

\subsection{Metode Pengujian Instrumen}

JURNAL

MANAJEMEN

INDONESIA

\section{Pengujian Validitas}

Vol.17 No.3

pengujian validitas untuk mengetahui sejauh mana ketepatan alat ukur dalam mengukur variabel yang diteliti. Riduwan (2007: 348), menyatakan bahwa validitas adalah suatu ukuran yang menunjukan tingkat kevalidan atau kesahihan suatu instrumen penelitian.

\section{Pengujian Reliabilitas}

Pengumpulan data yang dilakukan dengan menggunakan kuesioner memerlukan suatu pengujian reliabilitas, agar diketahui tingkat konsistensi atau keterpercayaan atas hasil jawaban responden terhadap instrumen yang digunakan. Riduwan (2007: 348) menyatakan bahwa reliabilitas menunjuk pada suatu pengertian bahwa suatu instrumen dapat dipercaya, maksudnya dalam beberapa pelaksanaan pengukuran terhadap kelompok yang sama diperoleh hasil yang relatif sama (konsisten) apabila pengukuran diulang lebih dari sekali.

\subsection{Metode Pengolahan dan Analisis Data}

Berdasarkan data yang diperoleh dari angket yang disebarkan kepada responden, maka perlu dilihat bagaimana gambaran objek yang akan diteliti dan seberapa besar pengaruh variabel-variebel bebas terhadap variabel terikat. Untuk mempermudah dan mempercepat proses perhitungan, pengolahan, data dalam penelitian ini, maka dilakukan dengan menggunakan bantuan program komputer SPSS (Statistical Product and Service Solution) For Windows Versi 22.0

\section{$4 \quad$ Hasil dan Pembahasan}

Data dikumpulkan dengan metode angket yang disebarkan ke Inspektorat Kota Bogor, Inspektorat Provinsi Jawa Barat, Badan Pengawasan Keuangan dan Pembangunan Provinsi Jawa Barat dan Badan Pemeriksa Keuangan (BPK) Perwakilan Provinsi Jawa Barat yang menjadi obyek penelitian dengan total responden 130 .

Hasil pengumpulan angket atau kuesioner yang kembali dan memenuhi syarat adalah sebagai berikut:

\begin{tabular}{lcc}
\hline \multicolumn{1}{c}{ Keterangan } & Jumlah & Presentase \\
\hline Kuesioner yang disebar & 130 & $100 \%$ \\
Kuesioner yang tidak kembali & 16 & $9 \%$ \\
Kuesioner yang kembali, & 114 & $91 \%$ \\
\hline Kuesioner yang memenuhi syarat & 114 & \\
Kuesioner yang tidak memenuhi syarat & 0 & \\
\hline
\end{tabular}

Dari tabel diatas dapat diketahui bahwa jumlah kuesioner yang disebar sebanyak 130 kuesioner (100\%). Kuesioner yang tidak kembali sebesar 16 kuesioner (9\%) dan kuesioner yang kembali sebanyak 114 kuesioner $(91 \%)$ dimana kuesioner yang memenuhi syarat sebanyak 114 kuesioner dan yang tidak memenuhi syarat sebanyak 0 kuesioner. 


\subsection{Persamaan Analisa Regresi Linear Berganda}

Analisis regresi linier berganda digunakan untuk mengetahui hubungan persamaan regresi

\section{JURNAL}

MANAJEMEN

INDONESIA

\section{Vol.17 No.3}

Desember 2017

Tabel 2. Hasil

Pengolahan Regresi

Linear Berganda pengaruh pressure $\left(x_{1}\right)$, opportunity $\left(x_{2}\right)$, rationalization $\left(x_{3}\right)$, capability $\left(x_{4}\right)$, terhadap fraud pengadaan barang di Pemerintah Kota Bogor $(y)$. Adapun hasil analisis regresi linear berganda dapat dilihat pada tabel berikut ini:

\section{Coefficients $^{\mathrm{a}}$}

\begin{tabular}{|c|c|c|c|c|c|c|}
\hline & \multirow[t]{2}{*}{ Model } & \multicolumn{2}{|c|}{$\begin{array}{l}\text { Unstandardized } \\
\text { Coefficients }\end{array}$} & \multirow{2}{*}{$\begin{array}{c}\begin{array}{l}\text { Standardized } \\
\text { Coefficients }\end{array} \\
\text { Beta }\end{array}$} & \multirow[t]{2}{*}{$\mathrm{t}$} & \multirow{2}{*}{ Sig. } \\
\hline & & B & Std. Error & & & \\
\hline \multirow{5}{*}{1} & (Constant) & 4.448 & 2.537 & & 1.753 & .082 \\
\hline & pressure & -.171 & .073 & -.217 & -2.355 & .020 \\
\hline & opportunity & .259 & .071 & .318 & 3.635 & .000 \\
\hline & rationalization & .091 & .040 & 172 & 2.252 & .026 \\
\hline & capability & .512 & .097 & 495 & 5.298 & .000 \\
\hline
\end{tabular}

a. Dependent Variable: fraud_pbj

Berdasarkan Tabel di atas Dua variabel independen (Opportunity dan Capability) secara individual mempunyai nilai signifikansi linearitas (sig. of linearity) sebesar 0,000 dan dua variabel independen Pressure mempunyai nilai signifikansi linearitas (sig. of linearity) sebesar 0,020 serta Rationalization mempunyai nilai linearitas (sig. of linearity) sebesar 0,026. Dengan demikian karena nilai sig of liniaerity kurang dari 0,05 (sig. of linearity < 0,05) maka dapat dikatakan semua variabel independen mempunyai hubungan yang linear terhadap variabel fraud pengadaan barang/jasa pemerintah.

\subsection{Uji F}

Tabel 3. Hasil

Pengolahan Uji F

Sumber: Data

Diolah (2017)
ANOVA $^{\mathrm{a}}$

\begin{tabular}{lrrrrr}
\hline Model & Sum of Squares & df & Mean Square & F & Sig. \\
\hline Regression & 619.491 & 4 & 154.873 & 21.415 & $.000^{\mathrm{b}}$ \\
Residual & 788.298 & 109 & 7.232 & & \\
\hline Total & 1407.789 & 113 & & & \\
\hline
\end{tabular}

a. Dependent Variable: fraud_pbj

b. Predictors: (Constant), capability, rationalization, opportunity, pressure

Berdasarkan tabel diatas diperoleh Nilai $F_{\text {hitung }}>F_{\text {tabel }}(21,415>2,4550)$ dengan nilai signifikansi adalah $0,000<0,050$ maka $\mathrm{H}_{0}$ ditolak dan $\mathrm{H}_{\mathrm{a}}$ diterima, artinya Pressure, opportunity, rationalization, dan capability secara simultan berpengaruh signifikan terhadap fraud Pengadaan Barang/Jasa Pemerintah. 
Coefficients $^{\mathrm{a}}$

\begin{tabular}{|c|c|c|c|c|c|c|}
\hline & & $\begin{array}{r}\text { Uns } \\
\mathrm{Cc}\end{array}$ & $\begin{array}{l}\text { Idardized } \\
\text { ficients }\end{array}$ & $\begin{array}{l}\text { Standardized } \\
\text { Coefficients }\end{array}$ & & \\
\hline & Model & B & Std. Error & Beta & $\mathrm{t}$ & Sig. \\
\hline 1 & (Constant) & 4.448 & 2.537 & & 1.753 & .082 \\
\hline & pressure & -.171 & .073 & -.217 & -2.355 & .020 \\
\hline & opportunity & .259 & .071 & .318 & 3.635 & .000 \\
\hline & rationalization & .091 & .040 & .172 & 2.252 & .026 \\
\hline & capability & .512 & .097 & .495 & 5.298 & .000 \\
\hline
\end{tabular}

a. Dependent Variable: fraud_pbj
JURNAL

MANAJEMEN

INDONESIA

Vol.17 No.3

Desember 2017

Tabel 4. Hasil

Pengolahan Uji t

Sumber: Data

Primer Diolah

(2017)

1. Berdasarkan hasil tabel diatas diperoleh nilai thitung untuk pressure sebesar $-2,355$, sedangkan

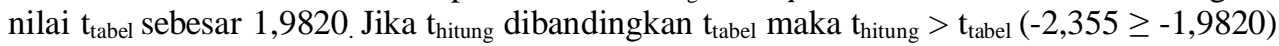
dengan nilai signifikasi yaitu $0,020<0,050$. Pengujian ini menunjukan bahwa $\mathrm{H}_{\mathrm{o}}$ ditolak dan $\mathrm{H}_{\mathrm{a}}$ diterima, artinya pressure secara parsial berpengaruh negatif dan siginifikan terhadap fraud Pengadaan Barang Jasa Pemerintah. Maka dapat disimpulkan bahwa secara parsial pressure berpengaruh negatif dan signifikan terhadap fraud Pengadaan Barang Jasa Pemerintah di Kota Bogor.

2. Berdasarkan hasil tabel diatas diperoleh nilai thitung untuk opportunity sebesar 3,635, sedangkan nilai $t_{\text {tabel }}$ sebesar 1,9820. Jika $t_{\text {hitung }}$ dibandingkan $t_{\text {tabel }}$ maka $t_{\text {hitung }}>t_{\text {tabel }}(3,635 \geq$ 1,9820 ) dengan nilai signifikasi yaitu $0,000<0,050$. Pengujian ini menunjukan bahwa $\mathrm{H}_{\mathrm{o}}$ ditolak dan $\mathrm{H}_{\mathrm{a}}$ diterima, artinya opportunity secara parsial berpengaruh positif dan siginifikan terhadap fraud Pengadaan Barang Jasa Pemerintah. Maka dapat disimpulkan bahwa secara parsial opportunity berpengaruh positifdan signifikan terhadap fraud Pengadaan Barang Jasa Pemerintah di Kota Bogor.

3. Berdasarkan hasil tabel diatas diperoleh nilai thitung untuk rationalization sebesar 2,252,

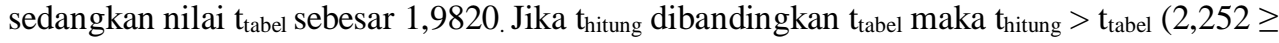
1,9820 ) dengan nilai signifikasi yaitu $0,026<0,050$. Pengujian ini menunjukan bahwa $\mathrm{H}_{\mathrm{o}}$ ditolak dan $\mathrm{H}_{\mathrm{a}}$ diterima, artinya rationalization secara parsial berpengaruh positif dan siginifikan terhadap fraud Pengadaan Barang Jasa Pemerintah. Maka dapat disimpulkan bahwa secara parsial rationalizationberpengaruh positifdan signifikan terhadap fraud Pengadaan Barang Jasa Pemerintah di Kota Bogor.

4. Berdasarkan hasil tabel diatas diperoleh nilai thitung untuk capability sebesar 5,298,

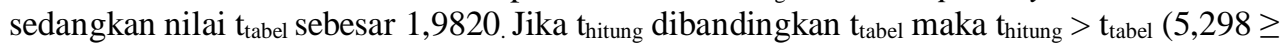
1,9820 ) dengan nilai signifikasi yaitu $0,000<0,050$. Pengujian ini menunjukan bahwa $\mathrm{H}_{\mathrm{o}}$ ditolak dan $\mathrm{H}_{\mathrm{a}}$ diterima, artinya capability secara parsial berpengaruh positif dan siginifikan terhadap fraud Pengadaan Barang Jasa Pemerintah. Maka dapat disimpulkan bahwa secara parsial capability berpengaruh positifdan signifikan terhadap fraud Pengadaan Barang Jasa Pemerintah di Kota Bogor. 


\section{Model Summary}

\section{JURNAL}

MANAJEMEN

INDONESIA

\section{Vol.17 No.3}

Desember 2017

Tabel 5. Koefisien

Determinasi

Sumber: Data

Primer Diolah

(2017)

\begin{tabular}{|c|c|c|c|c|c|c|c|c|c|}
\hline \multirow[b]{2}{*}{ Model } & \multirow[b]{2}{*}{$\mathrm{R}$} & \multirow{2}{*}{$\begin{array}{c}\mathrm{R} \\
\text { Square }\end{array}$} & \multirow{2}{*}{$\begin{array}{l}\text { Adjusted } \\
\text { R Square }\end{array}$} & \multirow{2}{*}{$\begin{array}{l}\text { Std. Error } \\
\text { of the } \\
\text { Estimate }\end{array}$} & \multicolumn{5}{|c|}{ Change Statistics } \\
\hline & & & & & $\begin{array}{l}\text { R Square } \\
\text { Change }\end{array}$ & $\begin{array}{c}\mathrm{F} \\
\text { Change }\end{array}$ & df1 & df 2 & $\begin{array}{l}\text { Sig. F } \\
\text { Change }\end{array}$ \\
\hline 1 &, $663^{a}$ & ,440 & ,419 & 2,689 & , 440 & 21,415 & 4 & 109 & ,000 \\
\hline
\end{tabular}

a. Predictors: (Constant), capability, ratoinalization, opportunity, pressure

Berdasarkan tabel diatas angka Adjusted $R$ Square atau koefisien determinasi adalah 0,419. Hal ini berarti 41,9\% variasi dari fraud Pengadaan Barang/Jasa Pemerintah bisa dijelaskan oleh variasi dari keempat variabel independen, sedangkan sisanya $(100 \%-41,9 \%=$ $58,1 \%$ ) dijelaskan oleh sebab-sebab lain.

\subsection{Pembahasan Hasil Penelitian}

Berikut ini merupakan pembahasan yang berkaitan dengan hasil penelitian mengenai fraud Pengadaan Barang/Jasa Pemerintah:

\subsubsection{Pengaruh pressure, opportunity, rationalization dan capability terhadap fraud pengadaan barang/jasa pemerintah}

Hipotesis pertama menyatakan bahwa pressure, opportunity, rationalization, dan capability secara simultan berpengaruh terhadap terhadap fraud Pengadaan Barang/Jasa Pemerintah, dalam hal ini dapat dikatakan pressure, opportunity, rationalization, dan capability dapat menunjang terjadinya fraud pengadaan barang/jasa pemerintah khususnya di Pemerintah Kota Bogor.

Hasil uji $\mathrm{F}$ yang positif akan menunjukkan bahwa terdapat pengaruh yang positif. Pengaruh yang positif tersebut dapat diartikan jika pressure, opportunity, rationalization, dan capability dapat menunjang terjadinya fraud pengadaan barang/jasa pemerintah di Kota Bogor, penelitian ini sejalan dengan Wolfe dan Hermanson (2004), orang yang melakukan fraud tersebut harus memiliki kapabilitas untuk menyadari pintu yang terbuka sebagai peluang emas dan untuk memanfaatkanya bukan hanya sekali namun berkali-kali. Teori ini menjelaskan bahwa kunci dalam memitigasi fraud adalah dengan fokus pada situasi khusus yang terjadi selain pressure dan rationalization serta kombinasi dari opportunity dan capability.

\subsubsection{Pengaruh pressure terhadap fraud pengadaan barang/jasa pemerintah}

Hipotesis kedua menyatakan bahwa pengaruh pressure terhadap fraud pengadaan barang jasa pemerintah. Hal ini menunjukan bahwa $\mathrm{H}_{\mathrm{o}}$ ditolak dan $\mathrm{H}_{\mathrm{a}}$ diterima, sehingga dapat disimpulkan bahwa pressure $\left(\mathrm{X}_{1}\right)$ berpengaruh negatif dan signifikan terhadap variabel fraud pengadaan barang/jasa pemerintah (Y) dalam pengadaan barang/jasa pemerintah di Kota Bogor. Adanya angka yang berpengaruh secara negatif dan signifikan ini berarti bahwa semakin meningkatnya tekanan/pressure, maka semakin berkurang kecenderungan untuk melakukan tindakan fraud pengadaan barang/jasa pemerintah. Dalam hal ini dapat di katakan bahwa semakin banyak tekanan/pressure pada proses pengadaan barang/jasa di Pemerintah Kota Bogor dari eksternal maupun internal dapat mencegah terjadinya fraud, dalam hal ini panitia lelang/pejabat pengadaan yang melaksanakan proses pengadaan barang/jasa dan pelaksanaan pengadaan barang/jasa tersebut akan berhati-hati pada saat evaluasi administrasi, teknis dan harga sehingga dapat meminimalisir terjadinya fraud sebab panitia lelang/pejabat pengadaan dan Pejabat Pembuat Komitmen yang bertanggung jawab proses sampai dengan pelaksanaan pengadaan barang/jasa pemerintah tersebut oleh karena itu intregitas panitia pengadaan barang/jasa disini sangat diperlukan untuk mencegah terjadinya fraud barang/jasa pemerintah.

Dalam pelaksanaan pengadaan barang/jasa pemerintah faktor-faktor yang mempengaruhi terjadinya fraud antara lain seperti gaya hidup, lingkungan yang mendukung, banyaknya yang

Jurnal Manajemen Indonesia 
berkepentingan, tuntutan atasan/kebutuhan organisasi atau untuk mendapatkan keuntungan pribadi, permintaan dana diluar Dokumen Pelaksanaan Anggaran (DPA) oleh pimpinan dan dana untuk Lembaga Swadaya Masyarakat (LSM), pelaku fraud tidak pernah tercatat melakukan kecurangan sebelumnya, pelaku fraud pengadaan Barang/Jasa bisa jadi mendapat tekanan dari atasan atau pihak lain yang memerlukan uang dari proses pengadaan secara tidak benar, adanya intervensi dari pihak manapun seperti atasan atau pihak lain memberikan tekanan kepada pelaku fraud pengadaan barang/jasa Pemerintah guna pengembalian ongkos politik yang cukup besar. Penyebab lain yang sangat naif adalah proses hukum (misalnya terkait pemberantasan korupsi) yang memerlukan biaya tinggi menimbulkan tekanan untuk melakukan kecurangan pada area yang lain.

Pencegahan terjadinya fraud dari faktor tekanan (pressure) adalah dengan cara memperbaiki ekosistem seperti dengan menggunakan $e$-procurement dan $e$-catalog pengadaan barang/jasa pemerintah, diharapkan penghasilan pegawai yang dibidang pengadaan barang/jasa ditingkatkan (dibedakan) dari pada Organisasi Perangkat Daerah (OPD) lainnya dalam hal ini adalah dari segi kesejahteraan pegawai yang dibidang tersebut, Pemerintah Kota Bogor harus lebih transparansi dalam hal pengadaan barang/jasa dan harus memperkuat sistem pengendalian internal setiap tahap demi tahap proses maupun pelaksanaan pengadaan barang tersebut. Hasil penelitian ini sejalan dengan Sihombing dan Rahardjo (2014) mengungkapkan bahwa pressure berpengaruh terhadap financial statement fraud. Kusuma dan Suranta (2017) juga mengungkapkan bahwa pressure berpengaruh terhadap fraud, tekanan yang berasal dari hutang sehingga pemerintah dapat melakukan pelaporan keuangan yang curang sebagai akibat tekanan akuntabilitas. Mansor, N. (2015) menyatakan bahwa pressure berpengaruh terhadap fraud, danManossoh, (2016) juga mengungkapkan bahwa pressure berpengaruh terhadap fraud, tetapi hal ini tidak sejalan Amaliah et al. (2016) dan Nursani et al. (2013) dan yang menyatakan bahwa pressure tidak berpengaruh negatif dan signifikan terhadap fraud.

\subsubsection{Pengaruh opportunity terhadap fraud pengadaan barang jasa pemerintah}

Hipotesis ketiga menyatakan bahwa opportunity berpengaruh terhadap fraud pengadaan barang jasa pemerintah. Hal ini menunjukan bahwa $\mathrm{H}_{\mathrm{o}}$ ditolak dan $\mathrm{H}_{\mathrm{a}}$ diterima, sehingga dapat disimpulkan bahwa secara parsial ada pengaruh siginifikan opportunity $\left(\mathrm{X}_{2}\right)$ terhadap fraud Pengadaan Barang/Jasa Pemerintah (Y). Maka dapat disimpulkan bahwa secara parsial opportunity berpengaruh positif terhadap fraud Pengadaan Barang/Jasa Pemerintah di Kota Bogor. Adanya angka yang berpengaruh secara positif dan signifikan ini mengindikasikan bahwa semakin meningkatnya opportunity maka akan meningkat pula fraud pengadaan barang/jasa pemerintah di Kota Bogor.

Jika kecurangan mengakibatkan pencurian terhadap sumber daya yang dimiliki pihak tertentu (Negara/Perusahaan), maka pencurian bisa terjadi apabila: ada yang bisa dicuri dan cara mencurinya, berapapun nilainya. Kesempatan/opportunity dalam fraud pengadaan barang/jasa pemerintah bisa terjadi karena peraturan atau SOP yang lemah, pengendalian internal lemah atau berjalan tidak semestinya, kepercayaan berlebihan atau tidak adanya pemilahan kewenangan yang baik.

Fraud pengadaan barang/jasa bisa terjadi karena adanya kesempatan/opprtunity seperti lemahnya pengawasan terhadap proses maupun pelaksanaan pengadaan barang/jasa pemerintah, kurangnya pengawasan dari atasan langsung, kurangnya kesadaran atas perbuatan yang salah, kurang menyadari bahwa pekerjaan itu berakibat hukum, prosedur/tahapan pengadaan barang/jasa tidak efektif diterapkan, kurangnya pengawasan yang baik kepada instansi terkait, panitia/pejabat pengadaan yang tidak jujur, tidak adanya orang yang membuka perbuatan kecurangan tersebut.

Pencegahan terjadinya fraud dari faktor kesempatan (opportunity) dalam pengadaan barang/jasa pemerintah telah dilakukan dengan perbaikan peraturan secara berkesinambungan dan otomasi pelaksanaan pengadaan, dimulai dari pengenalan pelelangan secara elektronik ( $e$ procurement, e-catalog), setiap pekerjaan yang akan dilaksanakan harus terlebih dahulu disesuaikan dengan kebutuhan agar sesuai dan pada saat pelaksanaan pekerjaan atasan terlebih dahulu memberi arahan yang sesuai dengan kegiatan yang akan dilaksanakan, mengganti 
personil unit layanan pengadaan kota bogor dengan orang yang baru yang lebih bersih dan profesional, meningkatkan kesadaran kepada pelaksana pengadaan barang/jasa tentang akibatakibat dari fraud terutama dari sisi religi/agama, menggunakan/melaksanakan probity audit oleh Aparat Pengawas Internal Pemerintah (APIP), Sistem Pengendalian Internal tahapan demi tahapan proses hingga pelaksanaan pengadaan barang/jasa pemerintah di Kota Bogor, meminimalisir pertemuan antara owner dan penyedia barang, selain ketentuan umum tersebut, ada banyak teknik pengendalian internal yang dapat dilakukan oleh masing-masing unit kerja yang terlibat dalam pelaksanaan Pengadaan Barang/Jasa Pemerintah.

Penelitian ini sejalan dengan penelitian Mansor (2015) yang mengemukakan bahwa opportunity berpengaruh signifikan terhadap terjadinya fraud. Kusuma dan Suranta (2017) mengungkapkan bahwa opportunity berpengaruh signifikan terhadap terjadinya fraud. Manossoh (2016) juga mengungkapkan bahwa opportunity berpengaruh signifikan terhadap terjadinya fraud. Sihombing dan Rahardjo (2014) mengungkapkan bahwa opportunity berpengaruh terhadap financial statement fraud. Sementara, Amaliah et al. (2016) mengungkapkan bahwa opportunity berpengaruh signifikan terhadap terjadinya fraud

\subsubsection{Pengaruh rationalization terhadap fraud Pengadaan Barang/Jasa Pemerintah}

Hipotesis keempat menyatakan bahwa pengaruh rationalization terhadap fraud pengadaan barang/jasa pemerintah. Hal ini menunjukan bahwa $\mathrm{H}_{\mathrm{o}}$ ditolak dan $\mathrm{H}_{\mathrm{a}}$ diterima, sehingga dapat disimpulkan bahwa rationalization $\left(\mathrm{X}_{3}\right)$ berpengaruh positif dan signifikan terhadap variabel fraud pengadaan barang/jasa pemerintah (Y) dalam pengadaan barang/jasa pemerintah di Kota Bogor. Adanya angka yang berpengaruh secara positif dan signifikan ini mengindikasikan bahwa semakin meningkatnya rationalization maka akan meningkat pula fraud pengadaan barang/jasa pemerintah.

Ada dua aspek pembenaran dalam fraud, yaitu : (1) pelaku merasa bahwa kemungkinan untuk mendapatkan keuntungan dari kecurangan lebih besar dari kemungkinan terdeteksinya kecurangan; dan (2) pelaku memiliki alasan pembenar atas perbuatannya, misalnya: gaji yang rendah dibandingkan dengan beban kerjanya, perbuatan dilakukan oleh banyak orang secara bersama-sama, perbuatan tersebut tidak merugikan siapapun, pelaku fraud hanya meminjam uang dan akan mengembalikannya, pelaku fraud beranggapan bahwa organisasi berhutang budi, tidak dihargai, hanya sementara sampai situasi keuangan membaik, pelaku fraud tidak bermaksud mencuri dan pelaku fraud bekerja keras dan pantas mendapatkannya.

Pencegahan terjadinya fraud dari faktor pembenaran (rationalization) dalam pengadaan barang/jasa pemerintah adalah dengan cara meningkatkan penghasilan dan pada saat yang sama dilakukan pengenaan saksi yang tegas apabila terjadi kecurangan (fraud), mengevaluasi menyeluruh dan memonitoring dari perencanaan sampai dengan pelaksanan pengadaan barang/jasa tersebut, pegawai yang bertugas dibidang pengadaan barang/jasa harus bertindak sesuai dengan norma agama dan hati nurani yang benar agar tidak terjadi fraud pengadaan barang/jasa di Pemerintah Kota Bogor, menggunakan/melaksanakan probity audit oleh Aparat Pengawas Internal Pemerintah (APIP), dan menggunakan pelelangan secara elektronik ( $e$ procurement, e-catalog). Hasil penelitian ini sejalan dengan penelitian yang dilakukan oleh Mansor (2015), Sihombing dan Rahardjo (2014), Manossoh (2016), Nursani et al. (2013) yang mengemukakan bahwa rationalization berpengaruh signifikan terhadap terjadinya fraud, tetapi penelitian ini tidak sejalan dengan penelitian yang dilakukan oleh Kusuma dan Suranta (2017) dan Amaliah et al. (2016) yang menyatakan bahwa rationalization tidak berpengaruh signifikan terhadap terjadinya fraud.

\subsubsection{Pengaruh capability terhadap fraud Pengadaan Barang/Jasa Pemerintah}

Hipotesis kelima dalam penelitian ini menyatakan bahwa pengaruh capability terhadap fraud Pengadaan Barang/Jasa Pemerintah. Hasil penelitian ini menunjukan bahwa $\mathrm{H}_{\mathrm{o}}$ ditolak dan $\mathrm{H}_{\mathrm{a}}$ diterima, sehingga dapat disimpulkan bahwa capability $\left(\mathrm{X}_{4}\right)$ berpengaruh positif dan signifikan terhadap variabel fraud Pengadaan Barang/Jasa Pemerintah (Y) dalam Pengadaan Barang/Jasa Pemerintah di Kota Bogor. Adanya angka yang berpengaruh secara positif dan 
signifikan ini mengindikasikan bahwa semakin meningkatnya capability maka akan meningkat pula fraud Pengadaan Barang/Jasa Pemerintah.

Dalam Pengadaan Barang/Jasa Pemerintah upaya organisasi dalam mencegah atau mendeteksi kecurangan dengan memperhatikan ketiga faktor tersebut belumlah cukup, dan oleh karena itu perlu mempertimbangkan faktor lain, Individual Capability yaitu sifat dan kemampuan pribadi seseorang yang memainkan peran besar yang memungkinkan suatu tindak kecurangan terjadi meskipun 3 faktor kecurangan (pressure, opportunity, dan rationalization) mendukung.

Analogi terhadap hal ini dapat diuraikan lebih lanjut bahwasanya kecurangan Pengadaan Barang/Jasa Pemerintah sebenarnya tidak akan terjadi tanpa ada orang yang tepat untuk melaksananya dan orang tersebut mempunyai kemampuan untuk melakukan kecurangan pengadaan barang/jasa dalam hal ini orang yang benar-benar mengetahui/mempunyai jabatan dalam Pengadaan Barang/Jasa di Pemerintahan, pegawai yang mampu memaksa sesorang untuk berbuat fraud, pegawai yang mampu berbohong agar tidak terdeteksi oleh rekan-rekan kerjanya, pegawai yang mempunyai kecerdasan dan kreatifitas dalam mengelola pengadaan barang/jasa sehingga tidak terdeteksi kalau pegawai tersebut melakukan fraud pengadaan barang/jasa misalkan dengan cara mengurangi spesifikasi barang tetapi tidak kelihatan bahwa spesifikasi barang tersebut berkurang, pandai mengambil peluang untuk melakukan fraud pengadaan barang/jasa dengan cara merencanakan pengadaan barang/jasa yang tidak dibutuhkan oleh organisasi, pegawai yang pandai menyimpan rahasia bahwa pegawai tersebut bersekongkol dengan pihak penyedia barang/jasa tersebut sehingga tidak terdeteksi kalau pegawai tersebut berbuat fraud pengadaan barang/jasa di Pemerintah kota Bogor. Peluang untuk melakukan kecurangan bisa saja terbuka, dorongan atau manfaat melakukan kecurangan bisa saja ada, dan bahkan perbuatan itu bisa saja dibenarkan karena alasan tertentu, tetapi harus ada orang yang memiliki kemampuan untuk melihat semua faktor tersebut sehingga terjadi fraud Pengadaan Barang/Jasa Pemerintah.

Pencegahan terjadinya fraud dari faktor capability pegawai dalam Pengadaan Barang/Jasa Pemerintah adalah dengan cara menggunakan/melaksanakan probity audit oleh Aparat Pengawas Internal Pemerintah (APIP) tahapan demi tahapan proses maupun pelaksanaan pengadaan barang/jasa di Pemerintah Kota Bogor, meminimalisir terjadinya fraud dengan cara dilaksanakannya pengadaan secara e-procurement dan e-catalog, pegawai yang bertugas dalam pengadaan barang/jasa harusnya menyadari bahwa perbuatan tersebut berakibat tindak pidana hukum, Pemerintah Kota Bogor harus mengganti pegawai yang bertugas di bidang pengadaan barang/jasa dengan orang yang berintregitas tinggi dan profesional. Hasil penelitian ini sejalan dengan penelitian yang dilakukan oleh R. Nursani, (2013), Mansor 2015), Amaliah et al. (2016), Sihombing dan Rahardjo (2014) yang mengungkapkan bahwa capability berpengaruh positif dan signifikan terhadap fraud, tetapi penelitian ini tidak sejalan dengan penelitian yang dilakukan oleh Kusuma dan Suranta (2017) yang menyatakan bahwa capability tidak berpengaruh dan signifikan terhadap fraud.

\section{$5 \quad$ Kesimpulan dan saran}

\subsection{Kesimpulan}

Berdasarkan hasil analisis dan pembahasan, maka dapat disimpulkan sebagai berikut:

1. Pengujian hipotesis secara simultan

Berdasarkan hasil penelitian yang diperoleh bahwa pressure, opportunity, rationalization dan capability secara simulatan berpengaruh terhadap fraud dalam pengadaan barang dan jasa pada Pemerintahan Kota Bogor. Artinya semakin tinggi faktorfaktor tersebut, maka akan semakin tinggi tingkat terjadinya fraud dalam pengadaan barang dan jasa. Hal ini juga membuktikan bahwa teori fraud diamond masih relevan digunakan untuk mengindentifikasi faktor; tekanan, kesempatan, ungkapan pembenaran dan 
kemampuan yang memotivasi seseorang melakukan fraud Pengadaan Barang/Jasa di Pemerintah Kota Bogor, disamping kolusi dalam memicu terjadi fraud.

\section{JURNAL}

MANAJEMEN

INDONESIA

\section{Vol.17 No.3}

Desember 2017
2. Pengujian hipotesis secara parsial

a. Berdasarkan hasil penelitian diperoleh bahwa pressure berpengaruh terhadap fraud Pengadaan Barang/Jasa di Pemerintah Kota Bogor. Pressure memiliki hubungan negatif terhadap fraud Pengadaan Barang/Jasa Pemerintah yang artinya semakin meningkatnya pressure/tekanan dalam Pengadaan Barang/Jasa Pemerintah maka semakin menurun tingkat terjadinya fraud Pengadaan Barang/Jasa Pemerintah di Pemerintah Kota Bogor.

b. Berdasarkan hasil penelitian diperoleh bahwa opportunity, rationalization dan capability berpengaruh terhadap fraud Pengadaan Barang/Jasa di Pemerintah Kota Bogor, yang artinya semakin meningkat opportunity/Kesempatan, rationalization dan capability dalam Pengadaan Barang/Jasa Pemerintah maka semakin meningkat pula tingkat terjadinya fraud Pengadaan Barang/Jasa Pemerintah di Pemerintah kota Bogor.

\subsection{Saran}

\subsubsection{Saran Praktis}

Berpengaruhnya pressure, opportunity, rationalization dan capability terhadap kecenderungan fraud dalam pengadaan barang dan jasa pada pemerintahan di Kota Bogor, membuktikan bahwa adanya tekanan oleh atasan, kesempatan, ungkapan pembenaran yang diikuti dengan adanya kemampuan individu dalam proses perencanaan sampai dengan pelaksanaan pengadaan barang dan jasa sebuah instansi dapat menjadi motivasi untuk melakukan terjadinya fraud. Sehingga hal ini harus diperhatikan oleh pihak Pemerintah Kota Bogor untuk menekan terjadinya fraud Pengadaan Barang/Jasa hal ini bisa dilakukan dengan cara sebagai berikut:

1. Setiap paket pekerjaan yang akan dilaksanakan harus terlebih dahulu disesuaikan dengan kebutuhan agar sesuai dan pada saat pelaksanaan pekerjaan atasan terlebih dahulu memberi arahan yang sesuai dengan kegiatan/paket pekerjaan yang akan dilaksanakan.

2. Diadakannya pengawasan dan memperkuat pengawasan terhadap Organisasi Perangkat Daerah (OPD) yang terkait dalam Pengadaan Barang/Jasa Pemerintah.

3. Menumbuhkan kesadaran atas perbuatan yang salah terhadap pegawai yang terlibat dalam Pengadaan Barang/Jasa.

4. Meningkatkan kesadaran kepada pelaksana pengadaan barang/jasa tentang akibat-akibat dari fraud terutama dari sisi religi/agama.

5. Diharapkan penghasilan pegawai yang dibidang pengadaan barang/jasa ditingkatkan (dibedakan) dari pada OPD Lainnya.

6. Diharapkan kedepan proses pengadaan dilaksanakan sesuai dengan etika pengadaan barang/jasa pemerintah.

7. Di lakukan probity audit oleh APIP.

\subsubsection{Saran bagi Penelitian Berikutnya}

Sebaiknya untuk peneliti selanjutnya mengembangkan kembali penelitian ini, karena masih terdapat beberapa faktor yang bisa diteliti selanjutnya, yang mungkin bisa mempengaruhi terjadinya fraud. Dan penggunaan Teori fraud diamond merupakan konsep yang paling banyak digunakan untuk mengindentifikasi faktor-faktor fraud dalam sektor korporasi dan publik. Oleh karena itu, bagi penelitian berikutnya disarankan menggunakan fraud pentagon dan faktorfaktor yang menyebabkan fraud lainnya.

\subsection{Keterbatasan Penelitian}

Penelitian ini telah diusahakan dan dilaksanakan sesuai dengan prosedur ilmiah, namun demikian masih memiliki keterbatasan yaitu faktor-faktor yang mempengaruhi fraud pengadaan

Jurnal Manajemen Indonesia 
barang/jasa Pemerintah di Kota Bogor dalam penelitian ini hanya terdiri dari empat variabel independen, yaitu pressure, opportunity, rationalization dan, sedangkan masih banyak faktor lain yang mempengaruhi fraud pengadaan barang/jasa Pemerintah di Kota Bogor, adanya keterbatasan penelitian dengan menggunakan kuesioner yaitu terkadang jawaban yang diberikan oleh sampel tidak menunjukkan keadaan sesungguhnya.

JURNAL

MANAJEMEN

INDONESIA

\section{Daftar Pustaka}

Amaliah, B. N., Januarsi, Y., \& Ibrani, E. Y. (2016). Perspektif fraud diamond theory dalam menjelaskan earnings management non-gaap pada perusahaan terpublikasi di Indonesia. Jurnal Akuntansi dan Auditing Indonesia, 19(1), 51-67.

Artantri, L. P. R. M., Handajani, L., \& Pituringsih, E. (2016). Peran E-Procurement terhadap Pencegahan Fraud pada Pengadaan Barang/Jasa Pemerintah Daerah di Pulau Lombok. Neo-Bis, 10(1), 16-32.

Cressey, D. R. (1950). The criminal violation of financial trust. American Sociological Review, 15(6), 738-743.

Deegan, C. (2013). Financial accounting theory. McGraw-Hill Education Australia.

Dowling, J., \& Pfeffer, J. (1975). Organizational legitimacy: Social values and organizational behavior. Pacific sociological review, 18(1), 122-136.

Ghozali, I., \& Chariri, A. (2007). Teori akuntansi. Semarang: Badan Penerbit Universitas Diponegoro.Priyatno, D. (2013). Mandiri Belajar Analisis Data dengan SPSS (Cetakan Pertama). Yogyakarta: Mediakom.

Gelderman, C. J., Ghijsen, P. W. T., \& Brugman, M. J. (2006). Public procurement and EU tendering directives-explaining non-compliance. International Journal of Public Sector Management, 19(7), 702-714.

Jatiningtyas, N., \& Kiswara, E. (2011). Analisis Faktor-Faktor yang Mempengaruhi Fraud Pengadaan Barang/Jasa Pada Lingkungan Instansi Pemerintah di Wilayah Semarang(Doctoral dissertation, Universitas Diponegoro).

Kusuma, I., Perdana, H. D., \& Suranta, S. (2017). Fraudulent Financial Reporting by District/Municipal Government in Indonesia. Asia Pacific Fraud Journal, 2(1), 27-48.

Manossoh, H. (2016). Faktor-Faktor Penyebab Terjadinya Fraud Pada Pemerintah Di Provinsi Sulawesi Utara. Jurnal Riset Ekonomi, Manajemen, Bisnis Dan Akuntansi, 4(1).

Mansor, N. (2015). Fraud Triangle Theory and Fraud Diamond Theory.Understanding the Convergent and Divergent For Future Research.International Journal of Academic Research in Accounting. Finance and Management Sciences, 1(5), 38-45.

Nursani, R., \& Irianto, G. (2013). Perilaku Kecurangan Akademik Mahasiswa: Dimensi Fraud Diamond. Jurnal Ilmiah Mahasiswa FEB, 2(2).

Priantara, D. (2013). Fraud auditing \& investigation. Jakarta: Mitra Wacana Media.

Riduwan, M. B. A. (2007). Skala pengukuran variabel-variabel penelitian. Bandung: Alfabeta.

Shocker, A.D., and Sethi, S.P. 1973. An approach to developing societal preferences in developing corporate action strategies, California Management Review, 15(4), pp, 97 105.

Sihombing, K. S., \& Rahardjo, S. N. (2014). Analisis Fraud Diamond dalam Mendeteksi Financial Statement Fraud: Studi Empiris pada Perusahaan Manufaktur yang Terdaftar di Bursa Efek Indonesia (BEI) Tahun 2010-2012 (Doctoral dissertation, Fakultas Ekonomika dan Bisnis). 
Sugiyono, D. (2006). Statistika untuk penelitian. Bandung: CV. Alfabeta.

Wolfe, D. T., \& Hermanson, D. R. (2004). The fraud diamond: Considering the four elements of fraud. The CPA Journal, 74(12), 38.

JURNAL

MANAJEMEN

INDONESIA

Vol.17 No.3

Desember 2017

Jurnal Manajemen Indonesia 